\title{
GIORDANO BRUNO Y LA RECUPERACIÓN DE LA PROPUESTA HERACLÍTEA ${ }^{1}$
}

\section{GIORDANO BRUNO AND THE RECOVERY OF THE HERACLITUS' PROPOSAL}

\author{
Diana María Murguía Monsalvo² \\ Universidad de Navarra
}

Recibido: 16-1-2015

Aceptado: 30-5-2016

Resumen. El texto muestra que Giordano Bruno, al retomar la visión filosófica de Heráclito, desarrolla junto con él una perspectiva compleja de la naturaleza, es decir, el reconocimiento de la integración de los elementos que la conforman, sin negar su divergencia y oposición. A través de la revisión de la unidad de los contrarios y de la concepción de la naturaleza como una y múltiple, se expone el paralelismo entre Heráclito y Bruno con su propuesta sobre la importancia de que la razón se asemeje al modo de ser de la naturaleza en la búsqueda de la integración de lo diverso.

Palabras clave: Heráclito; Giordano Bruno; unidad; unidad de contrarios; naturaleza.

\begin{abstract}
The author shows that when Giordano Bruno takes up again the Heraclitus' philosophical vision, develops along with him a complex perspective of nature. That is to say, he recognizes the unity or integration of the diversity of elements that conforms it, without denying its divergence and opposition. Through the revision of the unity of opposites and the conception of nature as one and multiple, it is shown the proposal of Heraclitus and Bruno: that the reason resembles the mode of being of the nature, in the search for the integration of the diverse.
\end{abstract}

Keywords: Heraclitus; Giordano Bruno; unity; unity of opposites; nature.

1. Este estudio forma parte del proyecto de investigación posdoctoral (2014-2016) desarrollado en la Universidad de Navarra con el auspicio del CONACyT de México. Mi agradecimiento a Mary Carmen García e Íñigo Sánchez.

2. (diana.murguiam@gmail.com) Doctora en Filosofía por la Universidad Nacional Autónoma de México (UNAM, 2011). Se ha dedicado al estudio de la filosofía del renacentista Giordano Bruno, así como al estudio de las fuentes que enriquecieron su pensamiento, tal como los filósofos presocráticos, Aristóteles, Nicolás de Cusa y los planteamientos copernicanos. Su labor se ha centrado en la metafísica y en la filosofía natural. Actualmente realiza una estancia de investigación posdoctoral en la Universidad de Navarra (2014-2015). 


\section{Introducción}

El cometido de este trabajo es doble. Por un lado, evidenciar que a través del estudio de la filosofía del renacentista Giordano Bruno (15481600) se abre una puerta para repensar y revalorizar la propuesta de los autores presocráticos, como el mismo Bruno hizo en su obra. Por otro (el cual será el centro del presente trabajo), mostrar que la perspectiva que Bruno reasume y adopta de Heráclito es su perspectiva compleja, es decir, la integración (de lo divergente) en la concepción de la naturaleza.

A lo largo de este trabajo utilizaré los términos "complejo" e "integrar" (con sus derivados: integración, integral, etc.), en sus significados comunes. Así, entiendo por "integrar" el hecho o acción de constituir un todo, a la fusión de dos o más elementos divergentes entre sí que los sintetiza. Y entiendo por "complejo" el conjunto o unidad de elementos diversos.

Intentaré mostrar que Heráclito y Bruno desarrollan una concepción "integral" y "compleja" de la naturaleza, es decir, que aceptan y señalan las diferencias, al tiempo que mantienen la unión y conformidad de las mismas. Ambos autores sostienen que la unidad del todo se encuentra, precisamente, en la no-eliminación (sino en la afirmación) de las divergencias.

Conviene percatarse de que esta perspectiva filosófica respecto de la conformación (como una y diversa) de la naturaleza conlleva, en paralelo, el empleo de un modo de razonamiento singular en el conocimiento de lo natural o lo real. Es decir, que la propuesta implica, a la vez, una variación en nuestro modo de razonar para buscar asemejarlo a ese modo de ser de la naturaleza, que es diferenciar en la unidad y unir en la diferencia.

Esto que parece "simple" de expresar, en el fondo significa un esfuerzo por superar o ampliar nuestro modus operandi racional que, habitualmente, en aras de clarificar, tiende a abstraer (separar), delimitar o desvincular. Mientras que el modo de operación de la naturaleza es el contrario: generar la interconexión de lo disímil, la creación de un conjunto de elementos y relaciones entrelazadas. Este aspecto irá reluciendo a lo largo del trabajo, pero se hará (o se intentará hacer) gráfico con la introducción y ayuda de un ejemplo sobre la imagen de un péndulo que al respecto de este tema nos ofrece Juan Antonio Sala en el libro Desde el punto de vista de la estimación, ${ }^{3}$ tal como señalaré en su momento.

Asimismo, y si bien he dicho que entenderé el término "complejo" en su significación común, incluiré y recogeré (de manera elemental) la mirada de la propuesta filosófica de Edgar Morin en torno al pensamien-

3. Sala, J. A.: Desde el punto de vista de la estimación. (Buscando las razones de valer de lo que vale... y a quien le valen). Editorial Círculo Rojo, 2012.

Thémata. Revista de Filosofía №54 (2016) pp.: 33-52. 
to complejo. Este autor señala que la complejidad «implica también, por principio, el reconocimiento de los lazos entre las entidades que nuestro pensamiento debe necesariamente distinguir, pero no aislar, entre sí». ${ }^{4} \mathrm{De}$ hecho, el mismo Morin recuerda que es con Heráclito donde nace el desafío de la comprensión de la naturaleza como una y múltiple. ${ }^{5}$

A modo de introducción a la relación filosófica de Bruno con el filósofo de Éfeso, cabe decir que, frente a la lectura de la obra bruniana, es digna de valorar la recuperación que hizo de los planteamientos de la sabiduría presocrática, pues en sus textos no encontramos una simple remembranza de las propuestas de la filosofía primigenia, sino una asimilación o bien una germinación de las tesis de los primeros filósofos griegos.

El interés de Bruno por el quid de la sabiduría presocrática, a saber, la naturaleza, lo une fuertemente con los antiguos filósofos. Y su proximidad con la postura heraclítea, en concreto, radica en la consideración que comparten respecto de un principio natural dinámico y permanente a la vez, que, al ser fuente de todas las cosas, es un principio que unifica en sí a los contrarios. ${ }^{6}$ Bruno adopta y desarrolla esta perspectiva heraclítea compleja de la naturaleza «[...] una filosofía que no esquiva la relación paradójica entre lo <uno y lo múltiple>», ${ }^{7}$ sino que admite y recoge ambos aspectos, como lo propio de la realidad natural.

Esta visión se patentiza de manera principal, pero no de manera exclusiva, en la concepción de la coincidencia de los contrarios, lo cuales nacen y se encuentran en un mismo principio. Es bajo esta perspectiva unitaria como ambos autores plantean un medio de acercamiento a la naturaleza que invita a ampliar el modo primario de la lógica que tiende a

4. Morin, E.: Introducción al pensamiento complejo. Trad. Marcelo Pakman, Barcelona: Gedisa, 1998, p. 23. Gustavo Fernández Pérez, a quien a lo largo de este estudio seguiré en algunos aspectos de la propuesta heraclítea, ha trabajado e incluido esta concepción del pensamiento complejo de Morin en su estudio del filósofo de Éfeso en: Fernández, G.: Heráclito. Naturaleza y complejidad, Sevilla/Madrid: Thémata/Plaza y Valdés, 2010.

5. Indica G. Fernández que así denomina Edgar Morin al pensamiento complejo: «[...] (unitas multiplex), situando su origen en Heráclito, quien atisba la multiplicidad en la unidad, así como la complementariedad de los contrarios. Lo uno es pues múltiple y complejo». Fernández, G.: op. cit., pp. 28-29.

6. La afinidad de Bruno con Heráclito no sólo se concentra en este par de temas. Puede además establecerse una asimilación entre el lógos de Heráclito (como regulador inmanente del proceso de cambio) con el intelecto universal bruniano, que es la causa eficiente del cosmos interna a la materia. Asimismo, desde una óptica más global, es posible visualizar una equivalencia en sus filosofías respecto de la interconexión que existe entre los elementos de la relación: hombre-naturaleza-divinidad, que abarca, incluso, el papel del conocimiento en ella. En la parte última de este trabajo se abordará alguna perspectiva de esta relación centrada en la correspondiente hombre-naturaleza, referida al conocimiento.

7. Fernández, G.: op. cit., p. 22.

Thémata. Revista de Filosofía №54 (2016) pp.: 33-52. 
discernir. Por el contario, la lógica de la unidad de los opuestos ${ }^{8}$ busca que, a la par que se distingue y se delimita lo diverso, también se vincule; y que observando el conjunto, las diferencias no se desdibujen.

La propuesta que ofrecen Heráclito y Bruno es mirar el todo sin dejar de mirar la parte, mirar lo múltiple y diverso a la par que lo uno y viceversa; no sólo la existencia sino la sincronía y sintonía de los opuestos. Es ahí donde, como dice Bruno, debe dirigirse aquél que decide emprender la búsqueda en torno a la verdad de la realidad natural: «[...] quien quiera conocer los más importantes secretos de la naturaleza, contemple y considere en torno a lo mínimo y lo máximo de los contrarios y opuestos». ${ }^{9} \mathrm{Y}$ es quizá aquello que Heráclito quiso traslucir al señalar que «la armonía oculta es superior a la manifiesta",${ }^{10}$ esa armonía superior que es totalidad opuesta en unidad.

En esta visión de la naturaleza como unidad de contrarios se integra la dinámica y la actividad propia del mundo natural, cuyo origen radica en un principio universal. Para ambos autores se trata de un principio de cambio, el cual, no sólo es agente sino, también, sustrato de trasformaciones. Es decir, un principio que es, a la vez, cambiante y permanente. Y es bajo este contexto como Bruno expresa su concordia con la visión del filósofo de Éfeso: «Por tanto, no ha de sonar mal a vuestros oídos la sentencia de Heráclito, el cual dijo que todas las cosas son uno, el cual [uno], en virtud de sus transformaciones, contiene en sí todas las cosas [...]».11

Para realizar la exposición dividiré en tres apartados los temas que abarcan la concepción de este principio universal. Dividiré estos aspectos

8. Como ahondaré en una nota más adelante, Nicolás de Cusa (1401-1464) -una de las grandes influencias del pensamiento bruniano- había advertido ya que la lógica aristotélica de la no-contradicción no es adecuada para una metafísica del infinito, donde rige la lógica de la unidad de los contrarios. Tanto Nicolás de Cusa como Giordano Bruno tienen como referente la lógica combinatoria de Raimundo Lulio (1232-1315), enteramente desvinculada de la lógica clásica. Asimismo, interesante es señalar que el poeta Samuel Taylor Coleridge -quien fuera un romántico inglés y lector de Bruno- quizá fue el primero en registrar el vínculo entre Heráclito y Bruno, reconociendo su afinidad en lo que el poeta llama la "lógica polar", es decir, la lógica de la coincidencia de los contrarios. Cfr. Gatti, H.: Essays on Giordano Bruno, Princeton: Princeton University Press, 2011, p. 8 y cap. 10.

9. Bruno, G.: Causa, BOEUC III 315 (p. 154). Edición crítica: De la cause, du principe et de l'un, trad. Luc Hersant, Vol. III. París: Belles Lettres, 1996. Traducción en castellano: De la causa, principio y uno, trad. Ángel Vasallo, Buenos Aires: Losada, 1941. Para citar a Bruno indicaré la referencia según la edición crítica de la obra bruniana: Euvres complètes de Giordano Bruno, París, Belles Lettres, que suele citarse: BOEUC más el número del volumen y el número de página. Incluiré también la traducción que uso en castellano con el número de página correspondiente, entre paréntesis.

10. DK 22 B 54. Para la citación de los fragmentos de Heráclito en castellano utilizo la versión de Mondolfo, R.: Heráclito. Textos y problemas de su interpretación. México, D.F.: Siglo XXI, 1966.

11. Bruno, G.: Causa, BOEUC III 289 (p. 144).

Thémata. Revista de Filosofía No54 (2016) pp.: 33-52. 
sólo para la exposición, pues debe comprenderse que se trata de ámbitos que, en ambas doctrinas, están intrínsecamente implicados: 1) El principio permanente del cambio universal, 2) la unidad de los contrarios y 3) la naturaleza como una y múltiple.

\section{El principio permanente del cambio universal}

Heráclito concibió al fuego como el principio natural y origen de todas las cosas. Zeller y Mondolfo consideran que el fuego heraclíteo es algo físico, es decir, que no sólo es un signo para representar la idea abstracta del cambio. ${ }^{12}$ Si bien el fuego de Heráclito es ciertamente un principio físico, adopto la posición de Fernández Pérez, para quien «el fuego es el aspecto físico de una fuerza metafísica [la fuerza universal y cósmica del movimiento] que crea, modela y destruye $[\ldots] » .^{13}$

Heráclito subraya la estable unicidad y universalidad de este principio, pero, al mismo tiempo, hace de su mutabilidad su característica principal: «todas las cosas se cambian recíprocamente con el fuego y el fuego, a su vez, con todas las cosas [...]». ${ }^{14} \mathrm{El} \mathrm{fuego} \mathrm{es} \mathrm{el} \mathrm{principio} \mathrm{agente}$ que se transforma en todo, es principio único variable. Está en continuo movimiento y transformación: de fuego se hace mar; del mar, la tierra y vapor ardiente; y de éstos, vuelve el fuego. ${ }^{15} \mathrm{El}$ cambio del fuego se patentiza como lo más propio del mundo natural.

Esta tesis ha hecho que Heráclito sea considerado en la historia del pensamiento como el filósofo del devenir. Sin embargo, debe advertirse que el cambio universal se sostiene en la inmutabilidad, mismidad y permanencia del principio, el cual es en sí mismo fuerza de transformación. En este sentido, Heráclito subraya ambos aspectos - mutabilidad y permanencia- del mismo principio que subyace a las trasformaciones y renace en

12. Cfr. Zeller, E. - Mondolfo, R.: La filosofia dei greci nel suo sviluppo storico, trad. Domenico Musti. Parte I, Vol. IV. Firenze: La Nuova Italia, 1968, pp. 82-92.

13. Fernández, G.: op. cit., p. 98.

14. DK 22 B 90.

15. Cfr. DK 22 B 31. Zeller hace notar que Heráclito no concibe cuatro elementos como después lo hará Empédocles, de modo que para el filósofo de Éfeso el aire no es una de las transformaciones del fuego. El Fragmento 76: «Vive el fuego la muerte de la tierra, y el aire vive la muerte del fuego; el agua vive la muerte del aire, la tierra la del agua», sería una adscripción por parte de los estoicos a Heráclito, según el historiador alemán. Cfr. Zeller, E.: Outlines of the History of Greek Philosophy. London: Routledge, 2001, p. 47. 
ellas. El fuego es cambiante y permanente. $\mathrm{O}$, en otros términos, la realidad es la permanencia del continuo devenir (del fuego primario).

Bruno, por su parte, también concibe un principio natural único que es «[...] sustrato del cual, con el cual y en el cual la naturaleza efectúa su operación, su obra, y que ella modela en tantas formas como nos presentan a los ojosn. ${ }^{16}$ Para Bruno ese principio es la materia, un constituyente universal a partir del cual las cosas se generan y que subyace a todas ellas.

Para explicar cómo es posible esta dinámica natural, es decir, la producción de tan diversas y variadas formas de la naturaleza a partir de una misma materia, Bruno hace un símil con la producción artística. La madera, por ejemplo, del tronco del árbol puede hacerse viga, mesa, un banquillo o una caja y, a pesar de los cambios, siempre mantiene su ser madera. Del mismo modo, en la naturaleza, siempre es una y la misma materia la que se constituye en la multiplicidad de formas naturales. ${ }^{17}$ Así como el fuego heraclíteo, la materia bruniana es principio universal cosmológico: «[...] aun variando al infinito y sucediéndose las formas las unas a las otras, es siempre una misma materia». ${ }^{18} \mathrm{Un}$ principio único que, permaneciendo sustancialmente el mismo, se configura en la diversidad.

Es importante señalar que para Bruno la materia universal, como sustrato de todas las cosas, es una materia vivificada por el alma del mundo y ambas constituyen una sustancia (de hecho, la única sustancia existente). La materia es principio potencial y el alma es principio actual, los cuales, si bien distinguibles lógicamente, se encuentran en unidad ontológica plena. Materia (potencia) y alma del mundo (acto, forma) constituyen, pues, la única sustancia: el universo infinito.

[...] el alma o la vida se encuentra en todas las cosas y, en mayor o menor grado llena toda la materia, por cierto que viene a ser el verdadero acto y la forma verdadera de todas las cosas. Por tanto, el alma del mundo es el principio formal constitutivo del Universo y de todo lo que en él se contiene. ${ }^{19}$

Ciertamente, Heráclito no concibe un alma del mundo, aunque, como jonio, no separa ni distingue la fuerza agente, activa y vivificante de aquello movido. En ese sentido, el universo y su principio son así concebidos: «Este cosmos, uno mismo para todos los seres [...] siempre ha sido, es y será fuego eternamente viviente, que se enciende según medidas

16. Bruno, G.: Causa, BOEUC III 175 (p. 91).

17. Cfr. Ibídem, pp. 173-179 (pp. 92-93).

18. Ibidem, p. 177 (p. 93).

19. Ibidem, p. 137 (p. 75).

Thémata. Revista de Filosofía No54 (2016) pp.: 33-52. 
y se apaga según medidas». ${ }^{20}$ En ambos pensadores tenemos un principio activo, que es en sí mismo agente y paciente del cambio.

Por eso señala Bruno que en la dinámica de la naturaleza, en ese proceso de transformación y generación de todo, lo que cambia, lo que es sujeto de variación, son las configuraciones particulares de las cosas, mas nunca su principio. La materia: «[...] permanece siempre fecunda y la misma [...] es y permanece siendo; y a las formas no hay que concebirlas sino como diversas disposiciones de la materia, que van y vienen, decaen y se renuevan $[\ldots] » .^{21}$

Esta concepción acaso recuerda a un par de sentencias heraclíteas, donde el filósofo expresa que la verdadera naturaleza de las cosas no nos es evidente. Por un lado, señala que "[...] la naturaleza suele ocultarse». ${ }^{22}$ Y, por otro, expresa también que «malos testigos son para los hombres los ojos y lo oídos de quienes tienen almas bárbaras». ${ }^{23}$ Pues si bien el cambio natural es patente, tras de él hay algo que se oculta, una fuerza permanente-cambiante que unifica la diversidad natural. He ahí la complejidad, pues, como señala Spengler, la transformación natural es evidente, no se pone en duda. Lo profundo del concepto del flujo heraclíteo radica en la intimidad del acontecer del universo. ${ }^{24}$

En el caso bruniano el proceso de sucesión de las formas naturales tiene por finalidad la existencia de todo el ser y vida posibles: la plena actualización ontológica. Por lo tanto, un mundo sin trasformación equivaldría a la muerte del universo, insostenible de suyo en una filosofía del infinito como la bruniana. La transformación es un proceso perenne e inagotable de la materia: «[...] nada disminuye substancialmente sino que todo, marchando a través del espacio infinito, cambia de rostro". ${ }^{25}$ Puede vislumbrarse que Bruno comprende de manera similar a Heráclito la dinámica natural: «[...] para el Efesio, la naturaleza es un proceso ígneo incesante pero estable, que da lugar a todas las cosas sin perder por ello su mismidad [...]». ${ }^{26}$ Ambos conciben la permanencia del principio cambian-

20. DK 22 B 30.

21. Bruno, G.: Causa, BOEUC III 191 (p. 98).

22. DK 22 B 123.

23. DK 22 B 107.

24. Cfr. Spengler, O.: Heráclito. Estudio sobre el pensamiento energético fundamental de su filosofía, trad. Augusta de Mondolfo, Buenos Aires: Espasa-Calpe, 1947, p. 37.

25. Bruno, G.: Infinito, BOEUC IV p. 41 (p. 72). Edición crítica: De l’infini, de l’univers et des mondes, trad. Jean-Pierre Cavaillé, Vol. IV, París: Belles Lettres, 2006. Versión en castellano: Sobre el infinito universo y los mundos. Traducción, prólogo y notas de Ángel Cappelletti, Buenos Aires: Aguilar, 1972.

26. Fernández, G.: op. cit., pp. 34-35.

Thémata. Revista de Filosofía No54 (2016) pp.: 33-52. 
te, o bien, la variabilidad de un mismo principio, el cual unifica el cambio, pues en la naturaleza el devenir es lo invariable.

Esta perspectiva referente al principio (uno y el mismo) del cosmos (múltiple y diverso), hace manifiesta la visión compleja de los dos pensadores y perfila el escenario de la unidad de los contrarios que Bruno encuentra en la concepción heraclítea. ${ }^{27}$

\section{La unidad de los contrarios}

Para Heráclito y Bruno, la fuerza productora de la naturaleza tiene su germen en sí misma: la realidad opuesta, que está presente ya desde el origen uno y diverso. Esta oposición fundamental del principio no sólo es la raíz, sino el sustento del mundo, como señala Heráclito: «Lo que se opone es concorde, y de los discordantes (se forma) la más bella armonía y todo se engendra por discordia». ${ }^{28}$

A través de la oposición -connatural al principio- se genera un proceso dinámico que es la naturaleza toda. Las transformaciones producen los opuestos físicos y la oposición (tensión) entre ellos permite y garantiza a su vez el equilibrio, la armonía y el orden natural. ${ }^{29}$ Esta visión heraclítea invita a vislumbrar que la discordia, si bien es polémica, también es concordia, es decir, que la contienda y el antagonismo, aunque discrepantes, son, asimismo causa de conformidad, unión y acuerdo. En otros términos, que la oposición en las trasformaciones de la naturaleza genera cambio, así como la corrupción suscita, a su vez, generación, vida, movimiento, es decir, la actividad propia del mundo, «[...] pues no habría armonía si no hubiera agudo y grave, ni animales si no hubiera hembra y macho, que están en oposición mutua». ${ }^{30}$

La oposición de los contrarios es, pues, simultáneamente, la misma armonía de la naturaleza, incluso porque la contrariedad tiene su origen y fundamento en la unidad del principio: «Y que esto no lo saben todos ni

27. Cfr. Montano, A.: «Bruno ed Eraclito» en (ed.) Lapini, W., Malusa, L., Mauro, L.: Gli Antichi e noi. Scritti in onore di Antonio Marco Battegazzore, vol., II. Genova: Brigati, 2009, p. 603.

28. DK 22 B 8.

29. Cfr. DK 22 B 53.

30. DK 22 B 9.

Thémata. Revista de Filosofía $\mathrm{N}^{\circ} 54$ (2016) pp.: 33-52. 
lo reconocen [...]: "No comprenden cómo lo divergente converge consigo mismo: armonía de tensiones opuestas [...]"». ${ }^{31}$

Ahora bien, en la propuesta bruniana, la suprema coincidencia de los contrarios es la coincidencia que existe entre la actualidad y potencialidad ontológicas, que es propia del principio del universo (materia y alma del mundo). Esta postura suya tiene sus raíces en la coincidentia oppositorum de Nicolás de Cusa y, propiamente, en su concepción del Possest ${ }^{32}$ como uno de los nombres que busca expresar la esencia divina. Giordano Bruno sostiene que si bien la coincidencia absoluta de los contrarios es característica divina, esa coincidencia se da igualmente en el ser del universo, al ser éste no sólo el efecto sino la manifestación más propia del infinito ser divino. Así, el universo es también infinito ${ }^{33}$ y, por ello, unidad de los opuestos:

En la esfera: largo, ancho y profundidad son lo mismo, porque tienen una misma dimensión: pero en el Universo, largo, ancho y profundidad son una misma cosa, porque son, por igual, sin término e infinitos. ${ }^{34}$

\section{DK 22 B 51.}

32. Cfr. Nicolás de Cusa, El Possest, (14), p. 160, en Nicolás de Cusa: Diálogos del idiota, El Possest, La cumbre de la teoría, trad. A. L. González, Colección de Pensamiento Medieval y Renacentista 19, Pamplona: Eunsa, 2008. Para Nicolás de Cusa, Dios -que es el Ser absoluto- es (en acto) todo lo que puede ser (en potencia), pues Dios es toda la posibilidad (ontológica) actualizada.

33. «En este sentido, [Bruno] abandonará la argumentación a favor de la trascendencia que atravesaba sin duda los textos del autor de La Docta Ignorancia. [...] Giordano Bruno tenía entonces claro que la atribución de la infinitud al que es el Absoluto, debía ir aparejada a la afirmación del carácter de infinito al universo que procede del primer principio». Soto M. J.: La metafísica del infinito en Giordano Bruno, Pamplona: Cuadernos de Anuario Filosófico. No. 47, 1997, p. 8. Si bien el universo bruniano es infinito como consecuencia del ser infinito divino y, además, el universo se concibe como vestigio y explicación del ser de Dios, el Dios de Bruno se comprende intrínseco a la naturaleza misma, lo cual -no es aventurado decirlo- se vislumbra del mismo modo en los planteamientos presocráticos. La de Bruno «es una filosofía que diviniza a la naturaleza y naturaliza a Dios». Cicuttini, L.: Giordano Bruno, Milán: Vita e Pensiero, 1950, p. 243. En el caso de Heráclito, el fuego y todo el cosmos que se deriva de sus transformaciones, está gobernado por el lógos, la razón inherente que regula el cambio del fuego: «Este cosmos [...] siempre ha sido, es y será fuego eternamente viviente, que se enciende según medidas y se apaga según medidas». (DK 22 B 30). Por eso señala Fernández Pérez que a la luz de sus antecesores jonios, la fuerza de la propuesta heraclítea radica precisamente en la noción de lógos más que en la de fuego «[...] que introduce el ritmo y la medida en el fuego [...]». G. Fernández, op. cit., p. 35. A la luz de estos fragmentos (incluso DK 22 B 41 y B 67) que conectan directamente con la temática de la coincidencia de los opuestos propia de la divinidad que gobierna, podría vislumbrarse la proximidad existente entre las filosofías del Efesio, del Cusano y la de Bruno.

34. Bruno, G.: Causa, BOEUC III 273 (p. 136).

Thémata. Revista de Filosofía №54 (2016) pp.: 33-52. 
El universo, en tanto que ser infinito, es todo lo que puede ser: es lo mayor que puede ser, al tiempo que es lo menor posible. Es máximo y es mínimo. Al ser la totalidad de las cosas, el ser infinito sólo puede ser uno, ya que si existiera otro, estaría limitado por éste y, por tanto, ya no sería infinito. Bruno extiende así la argumentación cusana de la realidad divina al ser del universo, afirmando que la totalidad de la naturaleza es la actualización de la potencialidad ontológica. El universo infinito - y ya no sólo Dios-es (en actualidad) todo lo que puede ser (en potencialidad), ${ }^{35}$ constituye la totalidad del ser, la totalidad de lo que existe:

[...] todas estas cosas particulares en el infinito no son esto y aquello, no son distintas [...] por tanto, el universo [...] porque lo comprende todo y no tolera este y aquel ser [...] es, por consecuencia, todo lo que puede ser; y en él [...] el acto no difiere de la potencia. ${ }^{36}$

La clave de esta afirmación bruniana está en la concepción de la materia. Este sustrato es la unidad de materia y forma (alma del mundo): siendo potencia de ser, es simultáneamente forma (actualidad), es y puede serlo todo ya que tiene la potencia (material) de ser todas las cosas, al mismo tiempo que es la potencia actual (formal) de todo. Así, el universo al «[...] comprender en su propio ser todas las oposiciones en unidad y armonía [...] en él todo es concorde». ${ }^{37}$

Debe repararse en el hecho de que la afirmación bruniana respecto de la infinitud del universo no es una afirmación menor. Su cosmología tuvo por finalidad desmantelar la cosmovisión clásica aristotélico-ptolemaica basada en el geocentrismo, geoestatismo, el sistema de esferas y la finitud del cosmos. Asimismo, y aun adoptando el giro copernicano, Bruno sobrepasa la postura de Copérnico, pues el sistema del astrónomo polaco aún mantiene la esfera límite del universo (la esfera de las estrellas fijas), así como la existencia de un único sol. Giordano Bruno elimina las esferas del universo, otorgando a los astros movimiento anímico propio. Retoma el sistema solar copernicano, pero lo multiplica infinitamente, señalando que todas las estrellas del firmamento son otros múltiples soles iguales

35. «Mientras que Bruno identifica a la materia infinita y animada como el objeto de la coincidencia, el Cusano identifica a Dios como el objeto de la coincidencia. [...] mientras 'Dios' significa el universo mismo en Bruno, esta palabra significa una entidad trascendente para el Cusano». Catana, L.: The concept of contraction in Giordano Bruno's philosophy, Aldershot: Ashgate, 2005, pp. 140-141.

36. Bruno, G.: Causa, BOEUC III 275 (p. 137).

37. Ibídem, p. 271 (pp. 135-136).

Thémata. Revista de Filosofía $\mathrm{N}^{\circ} 54$ (2016) pp.: 33-52. 
al nuestro, con sus planetas girando alrededor, habitando la infinitud del espacio. Lo relevante para nuestro tema es que esta cosmovisión tiene por sustento el principio de la coincidencia de los contrarios.

Los soles son calientes, son de fuego y brillan. Los vemos porque son más grandes que los planetas, los cuales son otras múltiples tierras similares a las nuestras, compuestas principalmente de agua, éstas son cuerpos fríos y opacos. Bruno explica la necesidad de la existencia de innumerables soles (estrellas) advirtiendo que, en un espacio infinito, un único sol no bastaría para trasmitir la luz y el calor vital. Por ello, en el espacio infinito existen diversidad de sistemas planetarios donde los cuerpos ígneos (soles) ocupan el centro, pues las tierras, que son frías, "dependen" de su calor para su conservación.

[...] son de por sí brillantes y calientes aquellos en cuya composición predomina el fuego; que los otros brillan por participación, son de por sí fríos y oscuros y en su composición predomina el agua, y que de esta diversidad y oposición dependen el orden, la simetría, la conexión, la paz, la concordia, la integración, la vida. De suerte que los mundos están compuestos por contrario y ciertos contrarios, como tierras y aguas, viven y crecen gracias a los otros, como soles y fuegos. Esto, según creo, es lo que quiso expresar aquel sabio el cual dijo que Dios produce la paz en los más altos contrarios, y aquel otro que sostuvo que el todo se mantiene unido por la lucha de los concordantes y por el amor de los antagonistas. ${ }^{38}$

38. Bruno, G.: Infinito, BOEUC IV 239 (pp. 181-182). Montano señala que el primer sabio evocado es Heráclito y el segundo es Empédocles. Cfr. Montano, A.: op. cit., p. 602. La tácita alusión a Heráclito podía hacer eco del fragmento 8: «Lo que se opone es concorde y de los discordantes [se forma] la más bella armonía»; y quizá del 67: «El Dios es día-noche, invierno-verano, guerra-paz, hartura-hambre, todos los opuestos [...]». Ahora bien, M. A. Granada indica que la primera evocación es una referencia al pasaje bíblico Job 25, 1-2: «Dios es poderoso y temible; él establece la paz en el cielo», y la segunda una alusión a Heráclito. Cfr. Bruno, G.: Del infinito: el universo y los mundos, trad. Miguel Ángel Granada, Madrid: Alianza, 1993, en Introducción, p. 52, nota 117. No concuerdo con Granada en que el segundo sabio aluda a Heráclito, ya que el filósofo de Éfeso no habla propiamente de discordia entre lo semejante, sino entre lo desemejante. Considero que Bruno refiere a Empédocles, a la función de las fuerzas de Amor y Odio, como podría ser lo expresado en el fragmento 21: «[...] En el Rencor todo es de formas diferentes y separadas, pero en el Amor todo confluye y se desea mutuamente. De ellos procede todo lo que fue, es y será en el futuro [...]» (DK 31 B 21). Kirk, G.S., Raven, J. E., Schofield, M.:, Los filósofos presocráticos: historia crítica con selección de textos, trad. Jesús García Fernández, Madrid: Gredos, 2008. Sin embargo, Granada parece acertar respecto del primer sabio evocado. Si bien el contenido del texto bíblico nos haría dudar de ello, la alusión conecta directamente con un pasaje de otra obra bruniana anterior: $L a$ cena de las cenizas, como el mismo Granada refiere. En La Cena Bruno menciona y muestra su empatía con el libro de Job, y lo relaciona con temas de su cosmología, concretamente con la armonía entre soles y tierras: Cfr. Bruno, G., Cena, BOEUC II 197-199 (p. 136). Edición crítica: Le souper des cendres, trad. Yves Hersant, Vol. II. París: Belles Lettres, 1994. Versión en castellano: La cena de las cenizas, Traducción, prólogo y notas de Miguel Ángel Granada, Madrid: Alianza, 1987. 
El universo se concibe como un todo orgánico y vivo. Y es aquí, en la cosmología bruniana, donde puede encontrarse uno de los principales ejemplos de la armonía de los contrarios de corte heraclíteo: la oposición (tierras-opacas-fías/soles-brillantes-calientes) genera concordia, ya que las tierras giran en torno a los soles porque eso las mantiene vivas y, recíprocamente, los soles dependen de la frialdad de las tierras que giran a su alrededor para equilibrar su calor, es decir, conservarse y asegurar su subsistencia.

Ante este escenario orgánico, Bruno plantea la habitabilidad de los astros, que descansa también en el hecho de no estar compuestos por un elemento único (el éter aristotélico), sino presentar diversidad de elementos y componentes: «no debéis imaginar que dichos mundos sean cuerpos de partes semejantes, porque no serían mundos, sino masas vacías, inútiles y estériles». ${ }^{39}$ Es decir que los cuerpos celestes por su diversidad de componentes, presentan formaciones naturales variadas (mares, valles, montañas, ríos, etc.), ${ }^{40}$ lo que genera y mantiene la vida dentro de ellos.

Es necesario, pues, por fin, que los dos fundamentos de las dos primeras cualidades activas contrarias sean igualmente constantes [...] y además que, así como este astro en el cual nos hallamos es de por sí frío y obscuro y en nada participa del calor y la luz si no en cuanto es calentado por el sol, así aquél sea de por sí caliente y luminoso y en nada participe del frío y la opacidad sino en cuanto es enfriado por los cuerpos circundantes y tiene en sí partes de agua, como la tierra tiene partes de fuego. Y, sin embargo, así como en este cuerpo frigidísimo, y ante todo frío y opaco, hay animales que viven por el calor y la luz del sol, así en aquél muy cálido y brillante los hay que subsisten por la refrigeración de los fríos circundantes [...]. ${ }^{41}$

Con la concepción bruniana de la actividad del universo a gran escala se pone de manifiesto en qué sentido la diversidad y la oposición generan movimiento, trasformación, devenir, en fin, vida, aquello que hace al universo ser lo que es: uno mismo con diversidad y oposición de elementos. $^{42}$ En el plano amplio y global, la conexión profunda que existe entre las partes opuestas se traduce en infinita interacción creadora que tiene su origen en un mismo principio fecundo. Y en línea con el filósofo de Éfeso, se

39. Bruno, G.: Infinito, BOEUC IV 193 (p. 154).

40. Cfr. Ibidem, 215 (p. 167).

41. Ibidem, 199 (p. 158).

42. Cfr. Montano, A.: op. cit., p. 603.

Thémata. Revista de Filosofía No54 (2016) pp.: 33-52. 
afirma que «[...] el principio debe poder contener en sí todos los contrarios y todos debe poderlos producir para realizar la concordia en la discordia». ${ }^{43}$

Ahora puede notarse la visión compleja (unidad que implica diversidad) de ambos filósofos. Ni Heráclito ni Bruno eliminan ni acallan la evidencia de la oposición sino, por el contrario, ratifican y afirman la existencia del contraste, de la disparidad, pues es justamente ello lo que lleva a exaltar su unidad y concordia. Se comprende entonces que «la armonía, en efecto, no es identidad ni supresión de la contrariedad", ${ }^{44}$ como ocurre con la vida que generan, procuran y mantienen las fuerzas brunianas opuestas de calor y frío, en los soles y tierras, como seres contrarios de fuego y agua. Los opuestos, aun en los extremos de la contrariedad, existen en relación armónica.

La apuesta de los dos filósofos es mirar ambas esferas de lo real: tanto la contrariedad y oposición como la armonía y la unidad. Es decir, afirmar la existencia efectiva de los extremos al mismo tiempo que se advierten no como escindidos, sino vinculados, interconectados y co-implicados.

Ahora bien, nuestro modo de conocer, de aproximación a la realidad, lo hacemos a través de la distinción, la separación, el discernimiento. Y esto es conveniente porque así hacemos asequible, digerible, la mixtura que ipso facto se nos presenta ante lo real. Discernir, esto es, distanciar ambos extremos, permite conocer, en cuanto que, como advierte J. A. Sala, el conocimiento como propio, descansa en el hecho de que el sujeto ante los polos otorga un valor (que vale) a uno de los extremos y niega valor (o bien, otorga un valor que no vale) al otro, es decir, al contario. Este autor advierte que «sin una estimación de valor no hay conocimiento humano posible», ${ }^{45}$ pues el sujeto se mueve otorgando (o no) valor a uno de los dos extremos. ${ }^{46}$

En la búsqueda del conocimiento nuestra mente se ciñe a la unipolaridad, separa y demarca (dando valor): "A o B", pero no "A y B" (uno o

43. Ibidem, p. 605.

44. Ídem.

45. Sala, J. A.: op. cit., p. 34.

46. Ibídem, p. 15. He reducido aquí a su mínima expresión la propuesta de Sala sobre lo que él denomina la gramática del valer que, parafraseando al mismo autor, es la inversión (por su valor contrario) a la gramática del ser. Esta propuesta tiene raíces en la lógica simbólica que considera los valores 1 y 0 , donde 1 representa el valor verdadero y 0 el valor falso o negación. Sin embargo, Sala va mucho más allá para proponer que en el conocimiento (en nuestra búsqueda de lo desconocido), el otorgamiento de valor 0 debe comprenderse como «[...] un movimiento del sujeto que a la par que afirma la ausencia de valor, lo mueve en busca del valor ausente». Ibídem, p. 66. El otorgamiento de valor le muestra al sujeto su preferencia por una de las opciones o extremos de la diferencia presentada, pues el sujeto se coloca en uno de los dos lados de la misma. Así, cuando el sujeto afirma que ha encontrado un valor, con esa misma afirmación indica su propia atribución de valor (el lado o el extremo en que se ha colocado). En este sentido, la gramática del valer es un intento por comprender «la naturaleza humana como buscadora de valores» (Ibidem, p. 36), y el conocimiento es «[...]

Thémata. Revista de Filosofía №54 (2016) pp.: 33-52. 
múltiple, pero no uno y múltiple, por ejemplo). En este sentido, es interesante vislumbrar que, en el fondo de la visión heraclítea y bruniana, radica una propuesta respecto de ampliar nuestro modo de conocer, para apostar por una mirada integral que, sin suprimir nuestra lógica, incorpore una visión global que integre y legitime ambos extremos. Esta idea se deja ver en la siguiente expresión bruniana:

[...] así como la belleza de un edificio no se manifiesta a quien percibe una mínima parte del mismo, cual una piedra, un cemento pegado, una media pared, sino sobre todo a quien puede ver el todo y tiene la facultad de comparar las partes entre sí. $^{47}$

Es una perspectiva que busca que nuestra aproximación racional al mundo se asemeje al modo de ser de la naturaleza, con la finalidad de conseguir una representación más ajustada a su ser real. Y es en ese sentido que tanto Heráclito como Bruno afirman la existencia de la diferencia de los contrarios (lo que admite la lógica tradicional), al tiempo que advierten su armonía y coincidencia (la mirada compleja o integral). Desde el punto de vista propiamente del pensamiento complejo, declara Morin que no se trata de renunciar a la lógica, ${ }^{48}$ sino de comprender que por sí misma, la

aprender a tratar con lo desconocido, sin que por ello pierda ese carácter de desconocido. A ese quehacer humano en que consiste el aprender a tratar le pertenece inmanentemente el valorar, estimar o apreciar. [...] Por lo tanto [...] sin estimación no habrá conocimiento alguno y allí donde encuentre conocimiento habrá inherentemente una apreciación realizada». Ibídem, p. 61. (Las cursivas son mías). Más adelante expondré en qué sentido la perspectiva de Sala puede ayudar a comprender la concepción compleja de Heráclito y Bruno, en el conocimiento de la realidad natural.

47. Bruno, G.: De Infinito, BOEUC IV 41 (pp. 72-73).

48. «El uso de la lógica es necesaria para la inteligibilidad, la supresión de la lógica es necesaria para la inteligencia». Morin, E.: El Método IV. Las ideas, p. 212, citado en: Fernández, G.: op. cit., p. 30. De hecho, con el planteamiento de la coincidencia oppositorum Nicolás de Cusa advirtió la limitación e insuficiencia de la lógica aristotélica (de la no-contradicción) en lo que respecta a la consideración del ser que es infinito. La lógica de la coincidencia de los contrarios afirma la posibilidad real de que un ser (el ser infinito) sea por sí mismo ambos extremos en la línea de oposiciones. Cfr. Nicolás de Cusa: Docta Ignorancia, I, c. IV. Ello, como expresa el Cusano, trasciende la lógica aristotélica, la cual conoce por distinción y oposición de objetos entre sí, lo que no tiene cabida en el conocimiento del infinito: «Este filósofo [Aristóteles] creyó firmemente que la afirmación contradice a la negación, y que ambas no pueden ser dichas a la vez de la misma cosa. Dijo esto por medio de la razón que concluye así que es verdadero. [...] Lo que él llama primer principio no es suficiente para mostrar el camino de la verdad, la cual es contemplada por la mente por encima de la razón». Nicolás de Cusa, El No-otro, Introducción, traducción y notas de Ángel Luis González, Pamplona: Cuadernos de Anuario Filosófico No. 180, 2005, (§88). Si bien la advertencia cusana está centrada en el planteamiento en torno a la distancia ontológica entre el ser finito y el ser infinito (Dios), el llamamiento por un cambio de lógica (y ontología) que otorgue reconocimiento a la unidad de la contrariedad, ya está señalada en Nicolás de Cusa.

Thémata. Revista de Filosofía $\mathrm{N}^{\circ} 54$ (2016) pp.: 33-52. 
lógica escinde. La comprensión compleja, por su parte, sin dejar de discernir, a la vez, integra. Y es precisamente ante estos órdenes heraclíteos que Sala expresa: «con Heráclito aprendí y encontré la certeza de que ambos valores contrarios valen»" ${ }^{49}$ Pues si el sujeto cognoscente, bajo el proceso del conocimiento otorga valor ya a uno ya a otro de los extremos, es posible también que, a pesar de la distancia que separa a los contrarios, el sujeto pueda dar valor (que vale) a ambos extremos, ya que «[...] siempre será posible desplegar una comprensión valiosa desde el valor contrario [...]». ${ }^{50}$ Es esto lo que se intentará exponer en el siguiente apartado, la comprensión compleja que integra ambos opuestos, a la par que afirma su condición de extremos. Es, como se ha revisado, la propuesta filosófica heraclítea y bruniana, al respecto de la naturaleza.

\section{La naturaleza como una y múltiple}

La propuesta sobre el conocimiento del mundo natural que no sólo reconoce la validez de la oposición sino que, simultáneamente, ratifica su unidad, en realidad puede resultarnos paradójica. Pues es cierto que, como señala A. C. Montes, el enfrentamiento o antagonismo parecen «[...] conducir, de manera natural, a la situación contraria, la de la no unificación de los factores que tan acremente luchan entre sím. ${ }^{51}$ Es decir que, si de hecho existe la oposición, parece "necio", o bien resulta "chocante" a la razón afirmar no sólo su unidad y concordancia, sino admitir por válidas y efectivas ambas posiciones.

Se trata de una propuesta de un cambio realizable en nuestro modo de aproximarnos a lo real. Una propuesta que se centra en procurar un movimiento que, desde nuestra razón, puede realizarse para que integremos a la vez que distinguimos: ver lo uno y ver lo múltiple, reconociendo, asimismo, que lo uno puede, al mismo tiempo, ser múltiple. ${ }^{52}$ Es el discurso de Heráclito y de Giordano Bruno, al comprender a la naturaleza como "una totalidad", es decir, como una al tiempo que es múltiple y, (simultáneamente), como múltiple al tiempo que es una. Así leemos en el

49. Sala, J. A., op. cit., p. 14.

50. Ibídem, p. 230.

51. Montes, A. C.: Repensar a Heráclito, Madrid: Trotta, 2011, p. 60.

52. Cfr. Morin, E.: op.cit., p. 15.

Thémata. Revista de Filosofía $\mathrm{N}^{\circ} 54$ (2016) pp.: 33-52. 
fragmento 10: "Conexiones: enteros y no enteros, convergente divergente, consonante disonante: de todo uno y de uno todon. ${ }^{53}$

La gramática del valer de Sala puede muy bien apoyarnos aquí. Seguiremos el mismo paradigma que él propone para mirar (con nuestra razón) los dos extremos como valores que valen: la multiplicidad y la unidad. Ambos extremos están integrados en la sentencia de todo uno y de uno todo, que (siendo extremos) se muestran concordes (como se vislumbra en el uso de la conjunción), simbolizando también toda esa diversidad existente de pares de opuestos.

Sala propone que esta sentencia del fragmento podemos pensarla imaginando un péndulo. Los extremos posibles hacia los cuales puede desplazarse el péndulo son, por un lado: 'todo' o 'todas las cosas' y, por el otro: 'uno', o 'la unidad'. El péndulo, que simboliza nuestra razón, se moverá de un extremo a otro y así, junto con el movimiento del péndulo, es decir, con nuestra razón en movimiento y sin dejar de ver a los extremos como tales, ambos se integrarán con el desplazamiento pendular. El movimiento de nuestra razón quedará descrito del siguiente modo:

[...] la bola atada por un fino cordel se moverá desde el extremo "todas las cosas" hacia el extremo "uno", y este movimiento quedará expresado como "todas las cosas "uno"'. El movimiento contrario se iniciará tras alcanzar el extremo "uno". En él, la bola del péndulo ha encontrado un límite que no puede traspasar, de hecho, por unos instantes se detendrá para comenzar el movimiento inverso expresado como "uno todas las cosas". De este modo comprendo el espacio abierto entre los extremos del péndulo como un espacio de comprensión, en el cual queda abarcado (luego comprendido) el movimiento que trascurre entre ambos extremos. [...] comenzará el movimiento inverso, que se dirigirá a comprender todas las cosas como "una", todas abarcadas por una única unidad. Toda cosa que cupiera situar en el espacio intermedio del recorrido quedaría determinada por su referencia a ambos contrarios: algo similar y, a la vez, perteneciendo al uno, esa unidad que abarca todas las cosas. ${ }^{54}$

La figura del péndulo es muy acertada porque nos deja ver que si pensamos en movimiento, es decir, de extremo a extremo (en integración), nuestro pensamiento no se "fija", es decir, no se queda inmóvil en uno de los polos y, por lo tanto, no escinde (mentalmente) lo que esta ligado (en lo real), por el propio movimiento natural. La paralización en uno de los extremos imposibilita -o limita- la opción de la panorámica global, de la mirada compleja que integra. Pues complejo es el «[...] pensamiento que delimita sin reducir ni desligar», ${ }^{55}$ lo cual (sólo) es posible comprendiendo

53. DK 22 B 10.

54. Sala, J. A.: op. cit., pp. 231 y 232 . He incluido una línea explícita para señalar el espacio que menciona el autor.

55. Fernández, G., op. cit., p. 27.

Thémata. Revista de Filosofía $\mathrm{N}^{\circ} 54$ (2016) pp.: 33-52. 
a los extremos como extremos y con nuestra razón en movimiento. Es así como se asimila a la naturaleza: que es permanencia y devenir.

Heráclito y Bruno nos representan así al mundo natural y también nuestro conocimiento. Nuestra razón puede moverse desde los dos extremos para descubrir la multiplicidad implicada en la unidad (del todo uno) y la unidad que implica multiplicidad ( $y$ de uno todo), recorriendo el mismo camino de la naturaleza. Bruno así lo expresa:

\footnotetext{
Además de esto, quiero que sepáis otros extremos de esta ciencia importantísima y de este solidísimo fundamento de las verdades y de los secretos de la naturaleza. En primer lugar, pues, quiero que notéis que es una y la misma la escala por la cual la naturaleza desciende a la producción de las cosas y [aquella] por la que el intelecto asciende al conocimiento de ellas; y que así la una [la naturaleza] como el otro [el intelecto] [partiendo] de la unidad llegan a la unidad, pasando por la multitud de intermediarios. ${ }^{56}$
}

Bruno pone de manifiesto que es la misma diversidad, esa de los intermediarios, la de las cosas múltiples, la del movimiento, de la vicisitud y del tiempo, aquello que (implícitamente) permite conocer la unidad, lo estable, lo eterno, lo permanente, lo coincidente, si penetramos de tal modo para no dejar de considerar el doble aspecto de las cosas. Retomando la idea del péndulo de Sala, en Bruno podríamos decir que en el principio (en un extremo del péndulo) las cosas son una unidad originaria en lo Uno. Conforme se da el movimiento del péndulo, es decir, del principio, se produce la transformación natural y con ello la multiplicidad, la contrariedad, lo variable, el mundo en toda su diversidad: el otro extremo. Así, el punto de llegada conserva en sí al punto de partida, y lo mismo con el movimiento de regreso. En este sentido, tal como es el camino de la naturaleza, será el camino del conocimiento: partiendo de lo uno, se llega a lo uno, pero atravesando toda la multiplicidad. Por ello advierte Védrine que en Bruno «[...] el problema del uno y de lo múltiple parece reducirse a una búsqueda metodológica pero se descubre rápidamente que expresa la ley fundamental del serm. ${ }^{57}$

Y es que el mundo, con sus innumerables especies, no es una diversidad de objetos ajenos entre sí, sino un mismo Uno, pues en la multiplicidad existe un vínculo entre todas las cosas que la componen: todas

56. Bruno, G.: Causa, BOEUC III 291 (p. 145).

57. Védrine, H.: La conception de la nature chez Giordano Bruno, París: Libraire Philosophique J. Vrin, 1967, p. 264.

Thémata. Revista de Filosofía Nº54 (2016) pp.: 33-52. 
provienen de una misma raíz y son, de suyo, un mismo principio. Es este el planteamiento de origen heraclíteo:

Heráclito no concibió una unidad que permaneciera al margen de la multiplicidad, sino una <unidad-multiplicidad > donde ambos elementos son indispensables e indisolubles, pues no sólo se refuerzan uno al otro, sino que incluso permanecen uno en otro, ya que nunca encontramos una multiplicidad pura sin ninguna presencia de la unidad y viceversa. Se trata, en definitiva, de una unidad que no se puede entender sin la multiplicidad $[\ldots] .^{58}$

A la luz de este contexto, es decir, mostrar que el mundo natural es un cosmos integrado, no escindido, sino una realidad "uniplural", 59 se ha intentado señalar la "invitación" que subyace en la filosofía heraclítea y en la de Bruno que la recoge. La propuesta es buscar vislumbrar, en todas sus dimensiones, el mundo en el que habitamos y que lo hagamos a través de la asimilación de nuestra razón al modo de ser de la naturaleza. De hecho, para Bruno, "filosofía" es equivalente al conocimiento de la naturaleza y los verdaderos filósofos son aquellos que hacen de la naturaleza la ley para la razón y no la razón ley para la naturaleza. ${ }^{60}$ Sea éste, acaso, también el sentido del fragmento 112: "Ser sabio es virtud máxima, y sabiduría es decir la verdad y obrar de acuerdo con la naturaleza escuchándola». ${ }^{61}$ Mismo espíritu filosófico que comparten Heráclito y Bruno: un intento de enfrentarse, sin escisiones, a comprender la naturaleza en su propiedad más íntima, aquella que la hace ser, a la vez, una y múltiple.

\section{Bibliografía}

Bruno, G.: CEuvres complètes: Le souper des cendres, trad. Yves Hersant, Vol. II, París: Belles Lettres, 1994; De la cause, du principe et de l'un, trad. Luc Hersant, Vol. III, París: Belles Lettres, 1996; De l’infini, de l'univers et des mondes, trad. Jean-Pierre Cavaillé, Vol. IV, París: Belles Lettres, 2006.

Traducción al castellano:

: De la causa, principio y uno, trad. Ángel Vasallo, Buenos Aires: Losada, 1941.

: Del infinito: el universo y los mundos, trad. Miguel Ángel

58. Fernández, G.: op. cit.,p. 34.

59. Cfr. Cappelletti, A.: en Introducción a Bruno, G.: Sobre el infinito universo y los mundos, p. 37.

60. Cfr. Montano, A.: Le radici presocratiche del pensiero di Giordano Bruno, Marigliano: LER, 2013, p. 35

61. DK 22 B 10.

Thémata. Revista de Filosofía $\mathrm{N}^{\circ} 54$ (2016) pp.: 33-52. 
Granada, Madrid: Alianza, 1993.

: La cena de las cenizas. Traducción, prólogo y notas de Miguel Ángel Granada, Madrid: Alianza, 1987.

: Sobre el infinito universo y los mundos. Traducción, prólogo y notas de Ángel Cappelletti, Buenos Aires: Aguilar, 1972.

Catana, L.: The concept of contraction in Giordano Bruno's philosophy. Aldershot: Ashgate, 2005.

Cicuttini, L.: Giordano Bruno. Milán: Vita e Pensiero, 1950.

Diels, H. A. y Kranz, W.: Die Fragmente Vorsokratiker. Berlín: Weidmannsche Verlagsbuchhandlung, 1960.

Fernández, G.: Heráclito. Naturaleza y complejidad. Sevilla/Madrid: Thémata/Plaza y Valdés, 2010.

Press, 2011.

Gatti, H.: Essays on Giordano Bruno, Princeton: Princeton University

Kirk, G.S., Raven, J. E., Schofield, M.: Los filósofos presocráticos: historia crítica con selección de textos, trad. Jesús García Fernández, Madrid: Gredos, 2008.

Mondolfo, R.: Heráclito. Textos y problemas de su interpretación. México, D.F.: Siglo XXI, 1966.

Montano, A.: «Bruno ed Eraclito" en (ed.) Lapini. W., Malusa, L., Mauro, L.: Gli Antichi e noi. Scritti in onore di Antonio Marco Battegazzore, vol. II. Genova: Brigati, 2009, pp. 595-615.

no, Marigliano (Napoli): LER, 2013.

Le radici presocratiche del pensiero di Giordano Bru-

Montes, A. C.: Repensar a Heráclito, Madrid: Trotta, 2011.

Morin, E.: Introducción al pensamiento complejo, trad. Marcelo Pakman, Barcelona: Gedisa, 1998.

Nicolás de Cusa: Diálogos del idiota, El Possest, La cumbre de la teoría, trad. A. L. González, Colección de Pensamiento Medieval y Renacentista 19, Pamplona: Eunsa, 2008.

: El No-otro, Introducción, traducción y notas de Ángel Luis Gonzá lez, Pamplona: Cuadernos de Anuario Filosófico No. 180, 2005.

Sala, J. A.: Desde el punto de vista de la estimación. (Buscando las razones de valer de lo que vale... y a quien le valen). España: Editorial Círculo Rojo, 2012.

Soto, M. J.: La metafísica del infinito en Giordano Bruno. Pamplona: Cuadernos de Anuario Filosófico. No. 47, 1997.

Spengler, O.: Heráclito. Estudio sobre el pensamiento energético fundamental de su filosofía, trad. Augusta de Mondolfo. Buenos Aires: Espasa-Calpe, 1947.

Védrine, H.: La conception de la nature chez Giordano Bruno. París: Libraire Philosophique J. Vrin, 1967.

Zeller, E., y Mondolfo, R.: La filosofia dei greci nel suo sviluppo storico, trad. Domenico Musti. Parte I, Vol. IV, Firenze: La Nuova Italia, 1968.

Zeller, E.: Outlines of the History of Greek Philosophy, London: Routledge 2001. 
